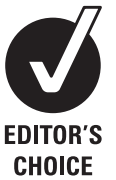

- Additional material is published online only. To view these files please visit the journal online (http://jnnp.bmj. com).

${ }^{1}$ Royal Edinburgh Hospital, Morningside Terrace, Edinburgh, UK

${ }^{2}$ Lancashire Traumatic Stress Service, Lancashire NHS Foundation Trust, Chorley, UK ${ }^{3}$ Department of Psychiatry, University of Edinburgh, Royal Edinburgh Hospital, Edinburgh, UK

Correspondence to Dr Amal Al Sayegh, Royal Edinburgh Hospital, Morningside Terrace, Edinburgh EH10 5HF, UK; amal.alsayegh@nhs.net

Received 1 June 2009 Revised 23 December 2009 Accepted 16 January 2010 Published Online First 27 August 2010

\title{
Psychological approaches to treatment of postconcussion syndrome: a systematic review
}

\author{
Amal Al Sayegh, ${ }^{1}$ David Sandford, ${ }^{2}$ Alan J Carson ${ }^{3}$
}

\begin{abstract}
Background and aim Postconcussion syndrome (PCS) is a term used to describe the complex, and controversial, constellation of physical, cognitive and emotional symptoms associated with mild brain injury. At the current time, there is a lack of clear, evidence-based treatment strategies. In this systematic review, the authors aimed to evaluate the potential efficacy of cognitive behavioural therapy (CBT) and other psychological treatments in postconcussion symptoms. Methods Four electronic databases were searched up to November 2008 for studies of psychological approaches to treatment or prevention of postconcussion syndrome or symptoms.

Results The search identified 7763 citations, and 42 studies were included. This paper reports the results of 17 randomised controlled trials for psychological interventions which fell into four categories: CBT for PCS or specific PCS symptoms; information, reassurance and education; rehabilitation with a psychotherapeutic element and mindfulness/relaxation. Due to heterogeneity of methodology and outcome measures, a meta-analysis was not possible. The largest limitation to our findings was the lack of high-quality studies. Conclusion There was evidence that CBT may be effective in the treatment of PCS. Information, education and reassurance alone may not be as beneficial as previously thought. There was limited evidence that multifaceted rehabilitation programmes that include a psychotherapeutic element or mindfulness/relaxation benefit those with persisting symptoms. Further, more rigorous trials of CBT for postconcussion symptoms are required.
\end{abstract}

\section{INTRODUCTION}

Most clinicians are familiar with the complex constellation of physical, cognitive and emotional symptoms complained of by patients in the aftermath of a mild traumatic brain injury (MTBI). Almost every aspect of the syndrome is controversial, including rates, mechanisms and even the name. MTBI has a high incidence with 100-300 hospital-treated cases/100 000 population per year in most industrialised countries; however, a large number of MTBI cases are not treated in hospitals, and the actual rate of all MTBI may be in excess of $600 / 100000 .{ }^{1}$ In the immediate aftermath of injuries, many patients describe a cluster of troubling symptoms (see table 1), but there is considerable controversy over the prognosis of such symptoms, with some authors arguing complete recovery within weeks ${ }^{2}$ and others suggesting highly disabling symptoms over years. ${ }^{3}$ The WHO helpfully conducted a high-quality systematic review of the epidemiological evidence and suggested that there are no MTBI attributable, objectively measured cognitive deficits beyond $1-3$ months postinjury in the majority of cases. ${ }^{4}$

There is also disagreement over the aetiological mechanism of these putative symptoms, with some authors believing that the presentation can be explained in terms of acquired neuropathological damage, ${ }^{5}$ although much of the evidence cited to support this is problematic. ${ }^{6}$ Many take the view that the mechanism involves a complex interplay of biological, psychological and social factors which include prior health, life stressors and compensation/litigation issues. ${ }^{4}$ Such a view on aetiology certainly explains why similar symptoms are described after orthopaedic injuries such as long bone fractures; why there is a highly variable rate of presentation from country to country; and why financial compensation is a significant risk factor. ${ }^{1}$ This debate is translated into the actual name for such symptoms. For many years, they have been referred to as postconcussion syndrome (PCS), and this tradition is continued in ICD-10 and DSM-IV. However, the WHO cautioned against this, saying that such a mechanism was at the current time unproven and reminded us of the age-old epidemiological rule that association was not proof of causation. ${ }^{4}$ We agree with the WHO's logic but have continued to use the term PCS in this review to describe those with persistent symptoms, as it remains the accepted term within ICD-10 and DSM-IV, the term that most clinicians are familiar with, and the term most commonly used in the studies we were systematically reviewing.

Perhaps the only area that clinicians do agree on is that there is a lack of clear, evidence-based treatment strategies to guide our clinical management of such patients. We consider that the development of these symptoms after MTBI appears to have much in common with a number of functional symptom syndromes such as chronic fatigue syndrome. ${ }^{7}$ We have noted the beneficial effects of cognitive behavioural therapy (CBT) in functional disorders ${ }^{8}$ and were interested in CBT's potential as a treatment for symptoms after MTBI. We noted with encouragement the suggestion that patients responded positively to appropriate information and reassurance given shortly after injury. ${ }^{9}$ This was in keeping with our view that there is a significant psychological component to more persistent complaints. However, we were unaware of any definitive randomised controlled trials of CBT in this group of patients. The purpose of this systematic review was to evaluate what, if 
Table 1 Postconcussion symptoms

\begin{tabular}{lll}
\hline Physical & Cognitive & Emotional \\
\hline Headache & Memory deficits & Irritability \\
Dizziness & Attention/concentration deficits & Depression \\
Fatigue & Executive function deficits & Anxiety \\
Visual disturbances & & \\
Noise sensitivity & & \\
Light sensitivity & & \\
Insomnia & & \\
\hline
\end{tabular}

any, clinical trial evidence existed on the efficacy of psychological therapies for the treatment of PCS.

\section{METHODS}

The sources of literature were the electronic databases Medline (1950-), Embase (1980-), PyschINFO (1967-) and CINAHL (1982-) up to the end of November 2008. The search strategy included the use of the following thesaurus terms: 'postconcussion syndrome,' 'brain concussion' and 'brain injuries.' In addition, we used the following keywords: 'brain contusion,' 'concussion,' 'postconcussion,' 'brain injury,' 'brain damage' and 'head injury.' In order to ensure that all relevant studies that used a psychological approach were identified, we combined the search strategy with keywords and, where available, subject headings including 'psychotherapy,' 'cognitive therapy,' 'cognitive behavioural therapy,' 'CBT,' 'behavioural therapy,' 'psychological therapy,' 'psychological treatment,' 'psychological techniques,' 'psychoeducation,' 'psychosocial,' 'biopsychosocial,' 'bibliotherapy,' 'computer-assisted therapy,' 'talking therapy,' 'rational emotive,' 'self-instruction,' 'self-management,' 'selfattribution' and 'non-surgical interventions.' Using the inclusion and exclusion criteria below, we reviewed the titles of all citations and retrieved relevant abstracts for more detailed evaluation. Where there was uncertainty, the full paper was studied. We also hand-searched the reference list of relevant studies to aid identification of further studies.

At the outset, we believed that there was only limited research in this field, and we therefore included data from pilot studies and case series as well as randomised controlled trials (RCT). We also decided to include studies that described a range of severities of head injury (including moderate and severe) if it seemed that the psychological intervention was addressing chronic problems in keeping with PCS. Finally, we included studies of patients with brain injuries due to non-traumatic causes.

\section{Inclusion criteria}

- Studies examining a psychological approach to treatment or prevention of postconcussion syndrome, postconcussion symptoms or other psychiatric or psychological problems after mild acquired brain injury;

- studies that included participants with moderate and severe head injuries if they also included MTBI;

- adult participants only;

- English language reports

\section{Exclusion criteria}

- Letters to editors and editorials without data;

- studies outside the timescales above, as these were not available electronically;

- studies excluding MTBI or those with Glasgow Coma Scale score of 13 or above;

- studies using purely neuropsychological/cognitive retraining;
- studies of rehabilitation programmes with no detail of psychotherapeutic elements.

The quality of each randomised controlled trial was assessed using the 22 -item CONSORT statement 2001 checklist $^{10}$ by AAS and DS. Where there was disagreement, AJC adjudicated.

\section{RESULTS}

The search strategy identified 7763 references and 42 were included in the systematic review. The inclusion and exclusion of papers is shown in figure 1. Psychological interventions fell into one of four categories:

1. use of CBT in postconcussion syndrome or with specific postconcussion symptoms;

2. information, reassurance and education;

3. rehabilitation programmes with a psychotherapeutic element;

4. mindfulness-based interventions and effects of stress/relaxation.

We found more randomised trial evidence than we expected and have therefore concentrated this report on data from RCTs but have presented our review of the remaining evidence as supplemental web files. The $17 \mathrm{RCT}$ discussed in this paper are presented in table 2 .

The participants are a heterogeneous sample of head injuries of various severity (including severe) in addition to those with postconcussion syndrome or symptoms from MTBI. The nonRCT studies and ratings of the RCTs using the CONSORT checklist are published as supplemental material online. For ease of reference, a summary of the RCTs is shown in table 3 showing the number of CONSORT items met, the intervention used, number of participants entering and at follow-up, length

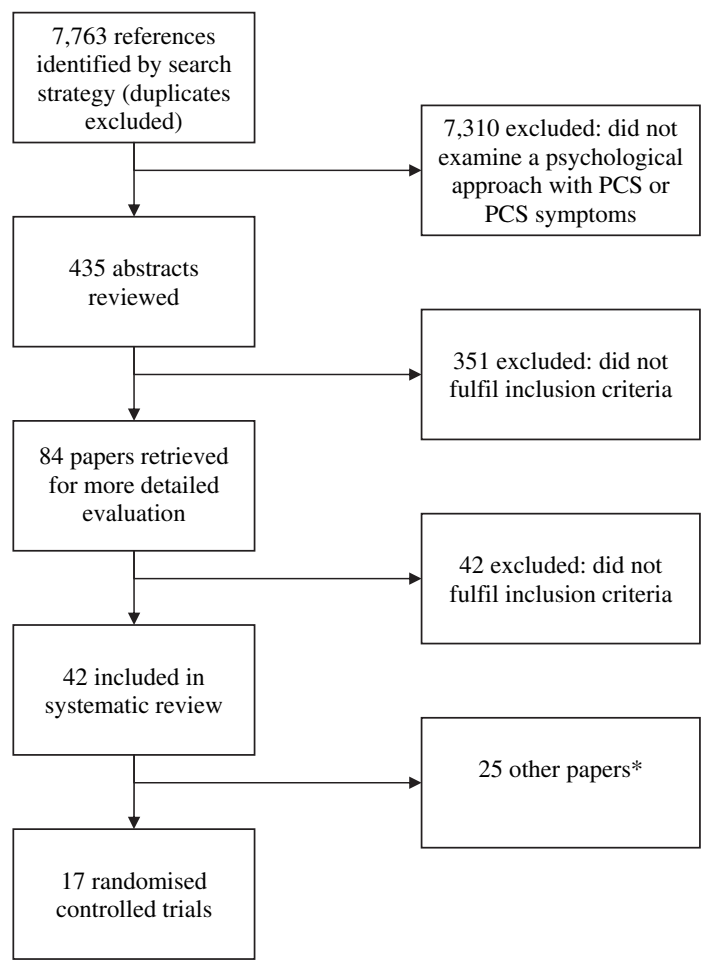

*Non-randomised controlled trials, non-controlled trials, retrospective studies, case series, case studies presented as on-line supplemental material.

Figure 1 Selection of papers. *Non-randomised controlled trials, non-controlled trials, retrospective studies, case series, case studies presented as on-line supplemental material. 


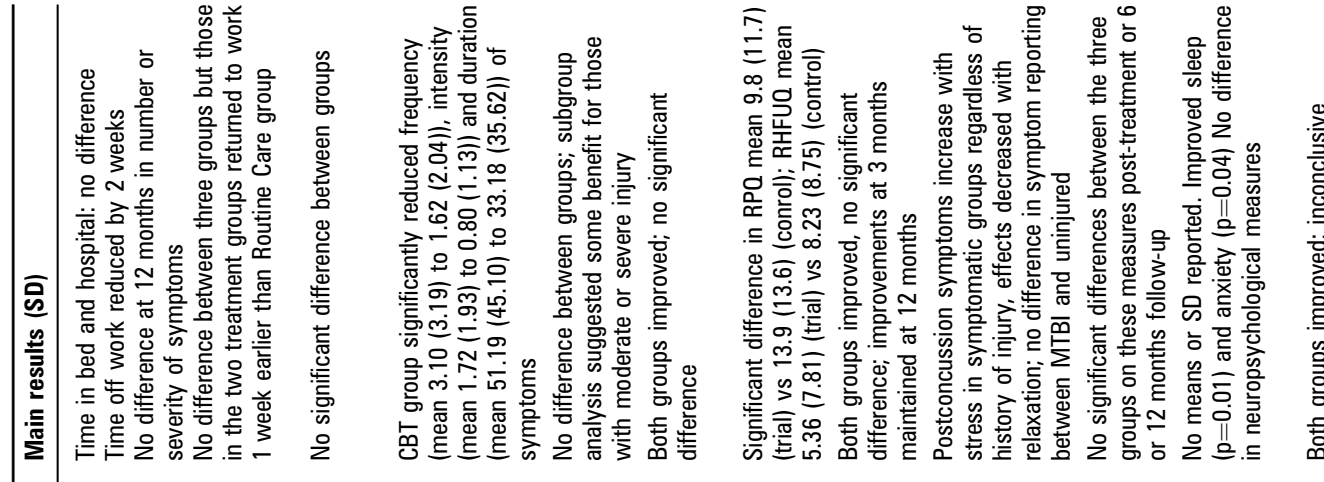

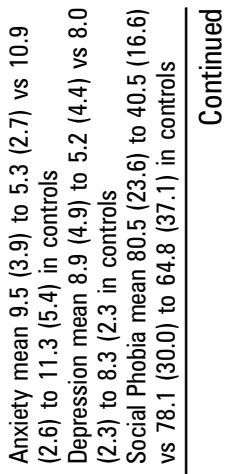

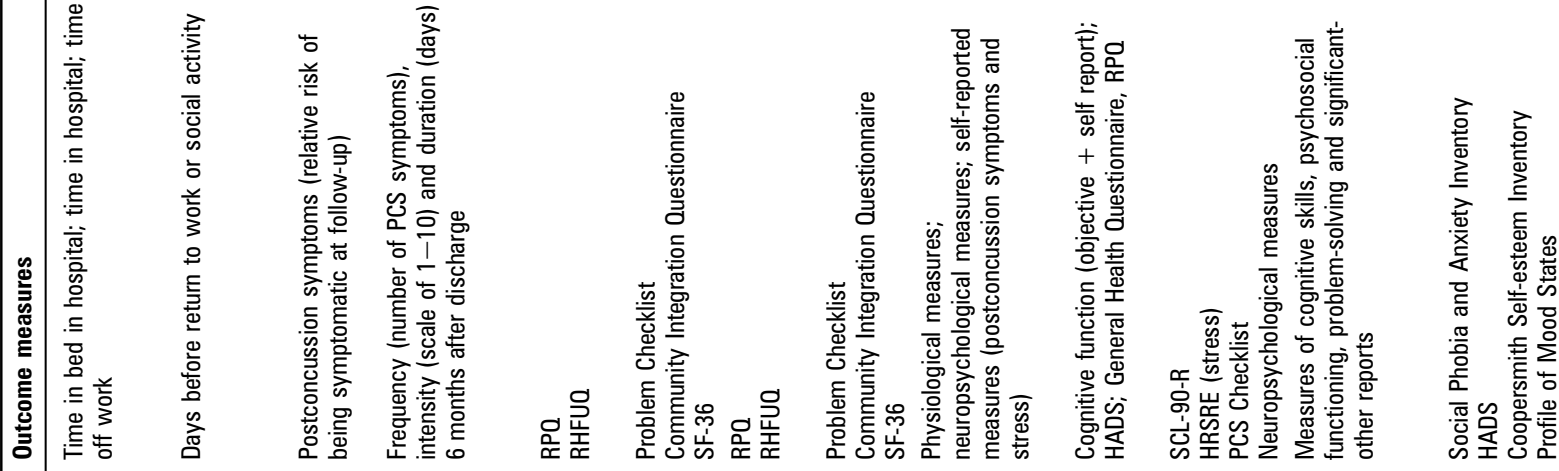

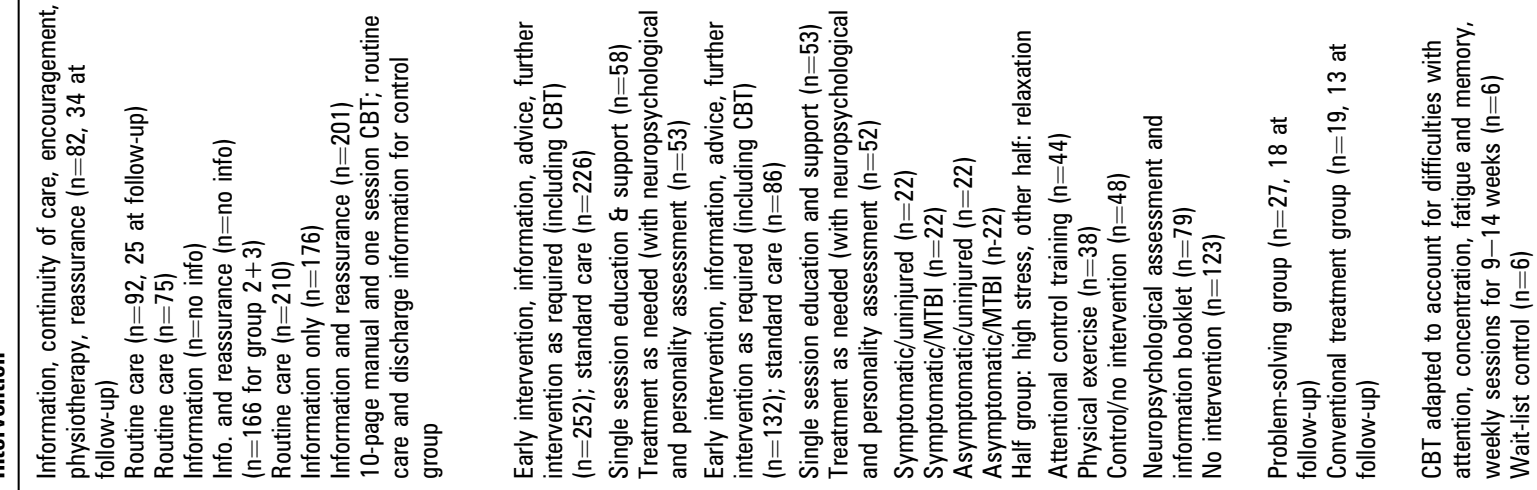

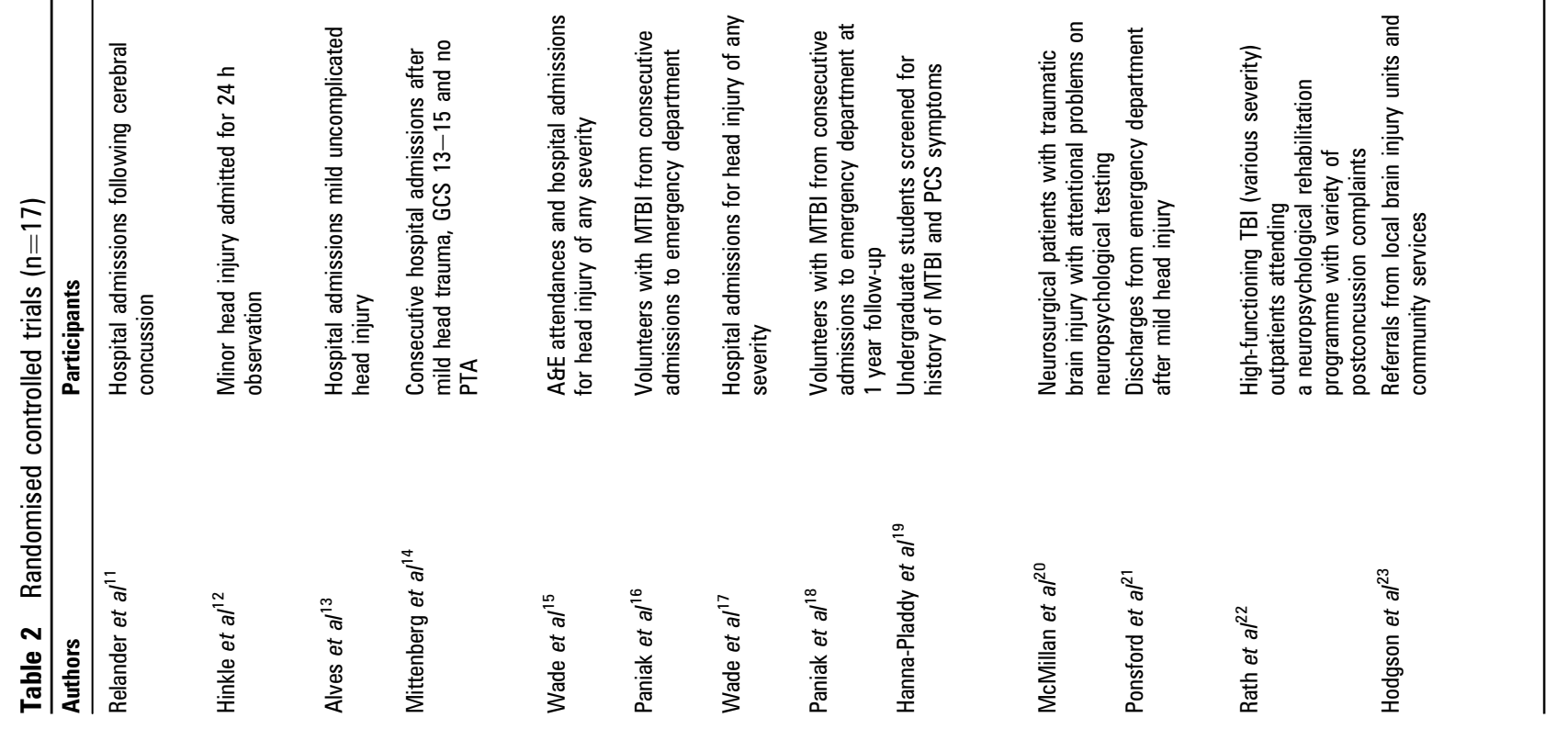




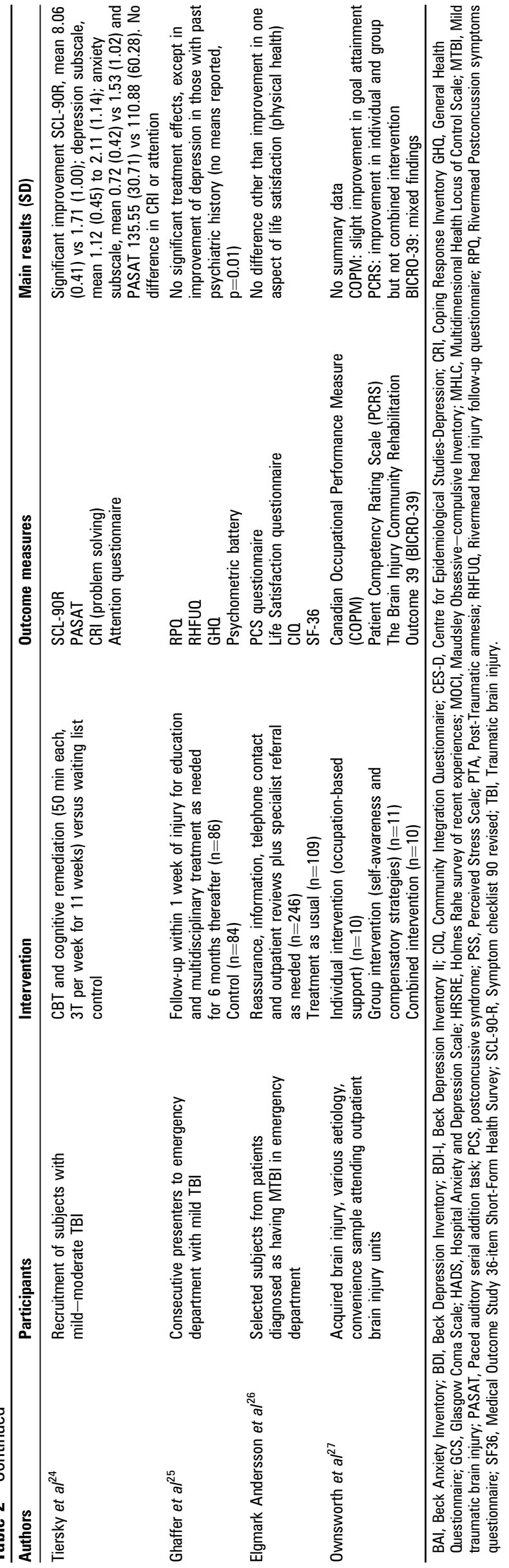

of follow-up, whether only participants with MTBI were included, the definition of MTBI used and whether a benefit was shown.

Due to heterogeneity of methodology and outcome measures, a meta-analysis of outcome was not possible. We gave consideration to calculating the effect sizes of these trials but opted not to, as we felt this would encourage a numerical comparison between studies which should not be compared in such a fashion.

\section{Evidence from RCTs}

Table 3 briefly describes a summative quality measure for each trial based on the number of 'CONSORT items' met. However, we caution that comparison of such total 'scores' is not necessarily informative, as each of the 22 items is given equivalent weight, whereas certain aspects of trials design, such as randomisation techniques, will have considerably more influence than, say, the structure of the discussion. A full qualitative assessment of each trial is detailed in the supplemental web material.

In general the RCTs reviewed performed well on giving the scientific background and rationale; eligibility criteria for participants; details of intervention intended for each group; specific objectives and hypotheses; and defined primary and secondary outcome measures. However, they were poor on reporting how sample size was determined; random allocation sequence was generated; allocation concealment was implemented; who generated the allocation sequence, enrolled participants and assigned them to groups; blinding was ascertained; the flow of participants; the dates defining periods of recruitment and follow-up; the use of intention-to-treat analysis and reporting important adverse events.

The definition of MTBI used varied between trials (table 3), and trials tended to use widely different outcome measures (table 2).

\section{Cognitive behavioural therapy}

There were three randomised controlled trials examining CBT, and all concluded some form of benefit. ${ }^{142324}$ Two of these met 11 of the 22 items on the CONSORT checklist. ${ }^{14}{ }^{23}$ One trial randomised consecutive hospital admissions after MTBI (GCS 13-15, no PTA) to one session of CBT and gave out a 10-page manual. ${ }^{14}$ In comparison with routine care, the CBT group reported reduced frequency, intensity and duration of symptoms at 6-month follow-up. The second trial randomised referrals from local brain injury units and community services, and delivered CBT to the treatment group adapted to account for difficulties with attention, concentration, fatigue and memory. ${ }^{23}$ Compared with the waiting list controls, the CBT group showed an improvement in anxiety and depression at 1-month follow-up. The third trial had a more robust methodology meeting 19 of the 22 CONSORT items. ${ }^{24}$ They recruited participants with mild-moderate TBI and delivered thriceweekly CBT (with thrice-weekly cognitive remediation) and concluded significant improvement in psychosocial functioning (especially anxiety and depression) but little change in cognitive measures. ${ }^{24}$ It is, perhaps, unfortunate that the stand-alone efficacy of CBT was not examined.

\section{Information, reassurance and education}

There were 10 papers that tested the efficacy of information, reassurance and education. ${ }^{11-13} \quad 15-18 \quad 21 \quad 25 \quad 26$ Generally this involved the early provision of information about diagnosis and possible postconcussion symptoms; reassurance about prognosis; education on ways of coping and resumption of activities. Some 
Table 3 Summary of trials

\begin{tabular}{|c|c|c|c|c|c|c|c|c|}
\hline & $\begin{array}{l}\text { No of CONSORT } \\
\text { items met } \\
\text { (max 22) }\end{array}$ & Intervention & No entering & $\begin{array}{l}\text { Number at } \\
\text { follow-up }\end{array}$ & $\begin{array}{l}\text { Follow-up } \\
\text { length }\end{array}$ & $\begin{array}{l}\text { Only } \\
\text { participants } \\
\text { with MTBI }\end{array}$ & MTBI definition & $\begin{array}{l}\text { Benefit } \\
\text { shown }\end{array}$ \\
\hline Relander et $a l^{11}$ & 7 & IER & 178 & 59 & 1 year & Yes & Excluded those requiring neurosurgery & No \\
\hline Alves et $a l^{13}$ & 7 & IER & 1710 & 587 & 1 year & Yes & GCS $13-15$, PTA $<24$ h & No \\
\hline Mittenberg et $a l^{14}$ & 11 & CBT & 58 & No info & 6 months & Yes & GCS $13-15$, PTA $<24 \mathrm{~h}$ & Yes \\
\hline Wade et $a l^{17}$ & 17 & IER & 314 & 218 & 6 months & No & Head injury requiring admission & Yes \\
\hline Paniak et $a l^{18}$ & 11 & IER & 119 & 105 & 1 year & Yes & ACRM 1993 MTBI definition & No \\
\hline Hanna-Pladdy et al ${ }^{19}$ & 8 & Relaxation & 88 & 88 & None & Yes & $\begin{array}{l}\text { Self-report closed head injury, } \\
\text { PTA }<24 \text { h }\end{array}$ & Yes \\
\hline McMillan et $a l^{20}$ & 10 & Mindfulness & 145 & 110 & 1 year & No & None & No \\
\hline Ponsford et al ${ }^{21}$ & 10 & IER & 262 & 202 & 3 months & Yes & $\begin{array}{l}\text { Trauma to head, LOC }<30 \text { min, } \\
\text { PTA }<24 \mathrm{~h}\end{array}$ & Yes \\
\hline Ghaffar et al ${ }^{25}$ & 14 & IER & 191 & 170 & 6 months & Yes & ACRM 1993 definition & No \\
\hline Elgmark et $\left.a\right|^{26}$ & 19 & IER & 395 & 355 & 1 year & Yes & ACRM 1993 definition & No \\
\hline Ownsworth et $\left.a\right|^{27}$ & 14 & Rehab & 35 & 31 & 3 months & No & ABI convenience sample & No \\
\hline
\end{tabular}

$\mathrm{ABI}$, acquired brain injury; $\mathrm{ACRM}$, American Congress of Rehabilitation Medicine; CBT, cognitive-behavioural therapy; GCS, Glasgow Coma Scale; IER, information, education and reassurance; LOC, loss of consciousness; PTA, post-traumatic amnesia.

incorporated multidisciplinary management tailored for individual needs. Two papers were considered as one trial, as they detailed different follow-up points on the same cohort of participants. $^{16} 18$

Three studies demonstrated a benefit. ${ }^{12} \quad 1721$ The first performed very poorly on the CONSORT checklist meeting only seven items and based its conclusions on a follow-up rate of $22 \%{ }^{12}$ The second ${ }^{17}$ repeated an earlier methodology ${ }^{15}$ and concluded that patients with moderate head injury requiring admission benefit from a routinely offered early intervention service but that no benefit was seen when such an intervention was offered to all patients presenting with a head injury. These studies were of higher quality meeting $16^{15}$ and $17^{17}$ CONSORT items. The third trial met 10 CONOSRT items and randomised emergency department discharges after MTBI and undertook neuropsychological assessments on the treatment group and gave them an information booklet. ${ }^{21}$ Compared with "no intervention,' they found improved sleep and anxiety, reduced distress but no difference in neuropsychological measures.

There were six RCTs in this category that concluded no benefit or reported inconclusive findings. ${ }^{11} 131516182526$ The quality of these trials varied greatly, meeting between 7 and 19 CONSORT items, and included the lowest and highest performers (table 3). These RCTs examined inpatient information, encouragement, physiotherapy and reassurance; ${ }^{11}$ inpatient information and reassurance; ${ }^{13}$ early intervention, information and further treatment as needed for those discharged from the emergency department; ${ }^{15}$ single session education and support in the emergency department; ${ }^{16} 18$ follow-up within 1 week of injury for education and multidisciplinary treatment as needed, ${ }^{25}$ and reassurance, information, telephone and outpatient reviews. ${ }^{26}$

Rehabilitation programmes with a psychotherapeutic element There were two RCTs that examined the efficacy of rehabilitation programmes that included psychotherapy. ${ }^{22} 27$ One concluded no difference between groups following the addition of a problem-solving intervention, but it was of low quality demonstrating only eight CONSORT items. ${ }^{22}$ The other reported mixed findings following the addition of individual and group support. It met 14 CONSORT items. ${ }^{27}$

\section{Mindfulness-based interventions and relaxation}

One trial tested the effects of relaxation on PCS symptoms and found that the severity of symptoms increased with stress in those reporting symptoms regardless of history of head injury, and the effects were reduced by relaxation. ${ }^{19}$ One trial examined a mindfulness-based intervention but found no difference between groups. ${ }^{20}$ Both trials met between $8^{19}$ and $10^{20}$ CONSORT items performing at the lower end of the range compared with the other trials (table 3 ).

\section{Evidence from non-randomised trials}

The details of interventions and main findings of studies of designs other than RCTs are available as online supplemental material but are summarised here.

\section{Cognitive behavioural therapy}

There were seven studies. One was a controlled trial which showed initial benefit, but this was not maintained at follow-up. ${ }^{28}$ Limitations included lack of power calculations to determine sample size and follow-up data not being analysed statistically. ${ }^{28}$ Three studies examined the use of CBT with the specific PCS symptoms of headache ${ }^{29}$ and insomnia, ${ }^{30} 31$ and all concluded an improvement in the symptom investigated. Limitations include inadequate $e^{29}$ or no control group ${ }^{31}$ and high drop-out rates. ${ }^{29} \mathrm{~A}$ case study examined the efficacy of CBT in treating anxiety and OCD after moderate traumatic brain injury and revealed significant improvements in most measures. ${ }^{32}$ Generalisability is limited, as the patient received concurrent cognitive rehabilitation. While the remaining two papers also concluded a positive outcome for CBT in the treatment of PCS, there were substantive methodological weaknesses including a potentially biased sample, no information on how subjects were selected from other referrals, no control group and lack of detail on how the investigators excluded a diagnosis of depression. ${ }^{33} 34$ 


\section{Information, reassurance and education}

There were three retrospective studies ${ }^{35-37}$ and one single case study. ${ }^{38}$ Two of the three retrospective studies considered a control group in the form of 'little/no treatment" ${ }^{\text {,35 }}$ or outcomes in those treated before a change in treatment was implemented. ${ }^{36}$ Both concluded a benefit. The third retrospective study had no control group and reported no difference in outcome. ${ }^{37}$ The single-case study reported a benefit. ${ }^{38}$

\section{Rehabilitation programmes with a psychotherapeutic element}

Thirteen studies examined the efficacy of rehabilitation programmes that included psychotherapy. Two papers were treated as one study, as they were published in two parts. ${ }^{39} 40$ Interventions and outcome measures varied greatly. The psychotherapeutic interventions were part of multidisciplinary rehabilitation, and so stand-alone efficacy was not studied. Generally there was little detail about the psychotherapy undertaken. Almost all the studies concluded a benefit but had no control group, ${ }^{39-44}$ had no randomisation ${ }^{45}$ or were case studies with a sample size of 1 or $2^{46-51}$ One retrospective study revealed inconclusive findings. ${ }^{52}$

\section{Mindfulness-based interventions}

In a pre-postdesign study with drop-outs as controls, no followup, high attrition rates and no control for medication, an improvement in measures of quality of life was concluded. ${ }^{53}$

\section{DISCUSSION}

Our systematic review on studies of the potential efficacy of CBT as a treatment for postconcussion symptoms found 10 studies, of which three had a randomised controlled design. All 10 studies concluded a benefit. However, they had relatively small numbers and short durations of follow-up, and do not allow robust conclusions about the efficacy of CBT to be drawn.

In general, the 17 RCTs we described in this review had methodological weaknesses, in particular, a failure to predetermine sample size, failure to detail the randomisation procedure, failure to ensure blinding (if indicated in the methodology) and failure to undertake intention-to-treat analyses. It is important that further trials in this field address these concerns. It is unlikely that further small-scale, methodologically limited studies will add any scientifically valuable information on treatment efficacy, and such investigations should be confined to pilot studies of procedural and methodological issues for definitive trials.

The benefits of information, education and reassurance in the treatment and prevention of PCS and PCS symptoms are generally endorsed in the MTBI literature. ${ }^{2} 954$ Yet our systematic review identified six randomised controlled trials that concluded no benefit versus three that demonstrated an improvement in symptoms. It may be argued that elements of this intervention may be justified as a cost-effective intervention to prevent the development of PCS, perhaps in selected patients, such as those whose head injury warranted admission, ${ }^{15} 17$ but we concluded that evidence to support its usefulness had been perhaps overstated.

The studies of rehabilitation programmes with a psychotherapeutic element were diverse in delivery, setting and content. The psychotherapeutic elements ranged from counselling and unspecified 'psychotherapy' to CBT. Outcome measures varied greatly, and a meaningful comparison was not possible. Generally, participants were those with persisting problems. Although most studies in this category showed a positive outcome, the studies with inconclusive findings or showing no difference were of more robust methodology. ${ }^{22}$ Generally, there was little information about the details of the psychotherapeutic component of the programme, and so it is difficult to draw conclusions, as stand-alone efficacy was not addressed. There was insufficient evidence to recommend these multifaceted programmes in the treatment of persisting PCS.

Based on the limited evidence found on mindfulness-based interventions and relaxation, these techniques cannot be currently recommended for prevention or treatment of postconcussion symptoms.

Limitations to our systematic review included publication bias with the assumption of a tendency to publish positive small trials but not small studies of no effect. Time constraints restricted contacting experts and researchers in the field for unpublished material. The inclusion criteria for individual studies were judged by only one author. However, we think the largest limitation to our conclusions was not our review methodology but the lack of high-quality studies examining the treatment and prevention of PCS. We had however anticipated this at the time of designing the study, and the aim was to describe the current, albeit limited evidence.

We believe that similarities can be drawn between PCS and complex functional symptom syndromes such as chronic fatigue syndrome. Most patients with fatigue are managed in primary care, but some may require referral to specialist care. Only a small proportion will be found to be suffering from a recognised medical disease. ${ }^{55}$ Patients may be worried that the fatigue is a symptom of severe but undiagnosed disease. This may lead to repeated presentations to health services and impairment in physical and social functioning. NICE guidelines recommend CBT and graded exercise as the most effective specialist treatment approaches. ${ }^{56}$ Focussing on symptoms and improving function tends to be more productive than engaging in a debate about the presence or absence of disease or undergoing repeated investigations and instrumentation. Parallels can be drawn with the experience of a patient disabled by PCS. We hope that a similar approach to managing PCS might be effective. The available data were not robust enough to make any firm conclusion in this regard. However, there are data to suggest that CBT shows some promise and that a definitive trial would be a useful contribution.

In the interim, we would also tentatively suggest that for the majority that present to emergency departments and primary care with MTBI, brief information and explanation should be provided, and it may be sufficient to manage any anxieties. For those that require further investigation or admission for observation, more tailored and specific information, education and reassurance is perhaps warranted to help prevent the development of PCS. This should include reassurance that cognitive difficulties are common and usually resolve by 3 months. There was support for the use of CBT, but it is likely to be a treatment for those with persisting problems or disability.

In conclusion, there was promising evidence that CBT may be effective in the treatment of PCS. Information, education and reassurance alone may not be as beneficial as previously thought. There was limited evidence that multifaceted rehabilitation programmes that include a psychotherapeutic element are of benefit in the management of persisting symptoms. Further and more rigorous randomised controlled trials of CBT for PCS are needed.

Acknowledgements We would like to thank B Pentland, for valuable comments on earlier draughts; A Mill and E Killean, for assistance in retrieving papers, and C Graham, for advice on statistics. 
Competing interests None.

Contributors AAS performed the search. AJC generated the study hypothesis and design. AAS and DS reviewed the original papers and rated quality of trials. AAS and AJC contributed to drafting the report.

Provenance and peer review Not commissioned; externally peer reviewed.

\section{REFERENCES}

1. Cassidy JD, Carroll LJ, Peloso PM, et al. Incidence, risk factors and prevention of mild traumatic brain injury: results of the WHO Collaborating centre task force on mild traumatic brain injury. J Rehabil Med 2004;43:28-60.

2. King NS. Post-concussion syndrome: clarity amid the controversy? Br J Med Hypn 2003:183:276-8.

3. Ryan LM, Warden DL. Post concussion syndrome. Int Rev Psychiatry 2003:15:310-16

4. Carroll LJ, Cassidy JD, Peloso PM, et al. Prognosis for mild traumatic brain injury: results of the WHO Collaborating Centre Task Force on Mild Traumatic Brain Injury. J Rehabil Med 2004:43:84-105.

5. Doezema D, King JN, Tandberg D, et al. Magnetic resonance imaging in minor head injury. Ann Emerg Med 1991;20:1281-5.

6. Carroll LJ, Cassidy JD, Holm L, et al. WHO Collaborating Centre Task Force on Mild Traumatic Brain, Injury. Methodological issues and research recommendations for mild traumatic brain injury: the WHO Collaborating Centre Task Force on Mild Traumatic Brain Injury. J Rehabil Med 2004:43:113-25.

7. Wessely S, Nimnuan C, Sharpe M. Functional somatic syndromes: one or many? [see comment]. Lancet 1999:354:936-9.

8. Kroenke K, Swindle R. Cognitive-behavioral therapy for somatization and symptom syndromes: a critical review of controlled clinical trials. Psychother Psychosom 2000;69:205-15.

9. Comper $\mathbf{P}$, Bisschop SM, Carnide N, et al. A systematic review of treatments for mild traumatic brain injury. Brain Inj 2005;19:863-80.

10. Moher D, Schulz KF, Altman DG. The CONSORT statement: revised recommendations for improving the quality of reports of parallel-group randomised trials. Lancet 2001;357:1191-4.

11. Relander M, Troupp H, Af Bjorkesten G. Controlled trial of treatment for cerebral concussion. BMJ 1972 30:777-9.

12. Hinkle JL, Alves WM, Rimell RW, et al. Restoring social competence in minor headinjury patients. J Neurosci Nurs 1986;18:268-71.

13. Alves W, Macciocchi SN, Barth JT. Postconcussive symptoms after uncomplicated mild head injury. J Head Trauma Rehabil 1993;8:48-59.

14. Mittenberg W, Tremont G, Zielinski RE, et al. Cognitive-behavioral prevention of postconcussion syndrome. Arch Clin Neuropsychol 1996;11:139-45.

15. Wade DT, Crawford S, Wenden FJ, et al. Does routine follow up after head injury help? A randomised controlled trial. J Neurol Neurosurg Psychiatry 1997;62:478-84.

16. Paniak C, Toller-Lobe G, Durand A, et al. A randomized trial of two treatments for mild traumatic brain injury. Brain Inj 1998;12:1011-23.

17. Wade DT, King NS, Wenden FJ, et al. Routine follow up after head injury: a second randomised controlled trial. J Neurol Neurosurg Psychiatry 1998;65:177-83.

18. Paniak C, Toller-Lobe G, Reynolds $\mathrm{S}$, et al. A randomized trial of two treatments for mild traumatic brain injury: 1 year follow-up. Brain Inj 2000;14:219-26.

19. Hanna-Pladdy B, Berry ZM, Bennett $T$, et al. Stress as a diagnostic challenge for postconcussive symptoms: sequelae of mild traumatic brain injury or physiological stress response. Clin Neuropsychol 2001;15:289-304.

20. McMillan T, Robertson $\mathrm{IH}$, Brock D, et al. Brief mindfulness training for attentional problems after traumatic brain injury: a randomised control treatment trial. Neuropsychol Rehabil 2002:12:117-25.

21. Ponsford J, Willmott C, Rothwell A, et al. Impact of early intervention on outcome following mild head injury in adults. J Neurol Neurosurg Psychiatry 2002;73:330-2.

22. Rath JF, Simon D, Langenbahn DM, et al. Group treatment of problem-solving deficits in outpatients with traumatic brain injury: a randomised outcome study. Neuropsychol Rehabil 2003;13:461-88.

23. Hodgson J, McDonald $\mathrm{S}$, Tate $\mathrm{R}$, et al. A randomised controlled trial of a cognitivebehavioural therapy program for managing social anxiety after acquired brain injury. Brain Impair 2005;6:169-80.

24. Tiersky LA, Anselmi V, Johnston MV , et al. A trial of neuropsychologic rehabilitation in mild-spectrum traumatic brain injury. Arch Phys Med Rehabil 2005;86:1565-74.

25. Ghaffar 0, McCullagh S, Ouchterlony D, et al. Randomized treatment trial in mild traumatic brain injury. J Psychosom Res 2006;61:153-60.

26. Elgmark Andersson E, Emanuelson I, Bjorklund R, et al. Mild traumatic brain injuries: the impact of early intervention on late sequelae. A randomized controlled trial. Acta Neurochir 2007;149:151-9, discussion 160

27. Ownsworth T, Fleming J, Shum D, et al. Comparison of individual, group and combined intervention formats in a randomized controlled trial for facilitating goal attainment and improving psychosocial function following acquired brain injury. J Rehabil Med 2008;40:81-8.

28. Anson K, Ponsford J. Evaluation of a coping skills group following traumatic brain injury. Brain Inj 2006:20:167-78.

29. Gurr B, Coetzer BR. The effectiveness of cognitive-behavioural therapy for post-traumatic headaches. Brain Inj 2005;19:481-91.

30. Ouellet MC, Morin CM. Cognitive behavioral therapy for insomnia associated with traumatic brain injury: a single-case study. Arch Phys Med Rehabil 2004:85:1298-302.

31. Ouellet MC, Morin CM. Efficacy of cognitive-behavioral therapy for insomnia associated with traumatic brain injury: a single-case experimental design. Arch Phys Med Rehabil 2007:88:1581-92.

32. Williams WH, Evans JJ, Fleminger S. Neurorehabilitation and cognitivebehaviour therapy of anxiety disorders after brain injury: an overview and a case illustration of obsessive-compulsive disorder. Neuropsychol Rehabil 2003;13:133-48.

33. Miller LJ, Mittenberg W. Brief cognitive behavioral interventions in mild traumatic brain injury. Appl Neuropsychol 1998;5:172-83.

34. Rees RJ, Bellon ML. Post concussion syndrome ebb and flow: longitudinal effects and management. Neurorehabilitation 2007;22:229-42.

35. Kelly R. The post-traumatic syndrome: an iatrogenic disease. Forensic Sci 1975:6:17-24.

36. Minderhoud JM, Boelens ME, Huizenga J, et al. Treatment of minor head injuries Clin Neurol Neurosurg 1980;82:127-40.

37. Gronwall D. Rehabilitation programs for patients with mild head injury: components problems, and evaluation. J Head Trauma Rehabil 1986;1:53-62.

38. Conboy TJ, Barth J, Boll TJ. Treatment and rehabilitation of mild and moderate head trauma. Rehabilitation Psychology 1986:31:203-15.

39. Cope DN, Cole JR, Hall KM, et al. Brain injury: analysis of outcome in a post-acute rehabilitation system. Part 1: general analysis. Brain Inj 1991;5:111-25

40. Cope DN, Cole JR, Hall KM, et al. Brain injury: analysis of outcome in a post-acute rehabilitation system. Part 2: Subanalyses. Brain Inj 1991;5:127-39.

41. Christensen AL, Pinner EM, Moller Pedersen P, et al. Psychosocial outcome following individualized neuropsychological rehabilitation of brain damage. Acta Neurol Scand 1992:85:32-8

42. Ownsworth TL, McFarland K, Young RM. Self-awareness and psychosocial functioning following acquired brain injury: an evaluation of a group support programme. Neuropsychol Rehabil 2000;10:465-84.

43. Vickery CD, Gontkovsky ST, Wallace JJ, et al. Group psychotherapy focusing on self-concept change following acquired brain injury: a pilot investigation. Rehabil Psychol 2006;51:30-5.

44. Geurtsen GJ, Martina JD, Van Heugten CM, et al. A prospective study to evaluate a new residential community reintegration programme for severe chronic brain injury: the brain integration programme. Brain Inj 2008;22:545-54.

45. Sarajuuri JM, Kaipio M, Koskinen SK, et al. Outcome of a comprehensive neurorehabilitation program for patients with traumatic brain injury. Arch Phys Med Rehabil 2005;86:2296-302.

46. Cicerone KD. Psychotherapy after mild traumatic brain injury: Relation to the nature and severity of subjective complaints. J Head Trauma Rehabil 1991;6: 30-43.

47. Montgomery GK. A multi-factor account of disability after brain injury: implications for neuropsychological counselling. Brain Inj 1995:9:453-69.

48. Mukherjee D, Reis JP, Heller W. Women living with traumatic brain injury: socia isolation, emotional functioning and implications for psychotherapy. Women Ther 2003:26:3-26

49. Mateer CA, Sira CS, O'Connell ME. Putting humpty dumpty together again: the importance of integrating cognitive and emotional interventions. J Head Trauma Rehabil 2005:20:62-75

50. Coetzer R. Psychotherapy following traumatic brain injury: integrating theory and practice. J Head Trauma Rehabil 2007;22:39-47.

51. Arco L. Neurobehavioural treatment for obsessive-compulsive disorder in an adult with traumatic brain injury. Neuropsychol Rehabil 2008;18:109-24.

52. Cicerone KD, Smith LC, Ellmo W, et al. Neuropsychological rehabilitation of mild traumatic brain injury. Brain Inj 1996;10:277-86.

53. Bedard M, Felteau M, Mazmanian D, et al. Pilot evaluation of a mindfulness-based intervention to improve quality of life among individuals who sustained traumatic brain injuries. Disabil Rehabil 2003:25:722-31.

54. Mittenberg W, Canyock EM, Condit D, et al. Treatment of post-concussion syndrome following mild head injury. J Clin Exp Neuropsychol 2001;23:829-36.

55. Sharpe M, Wilks D. Fatigue. BMJ 2002;325:480-3.

56. National Institute for Health and Clinical Excellence (NICE). Chronic fatigue syndrome/myalgic encephalomyelitis (or encephalopathy): diagnosis and management of chroinc fatigue syndrome/myalgic encephalomyelitis (or encephalopathy) in adults and children. (NICE guideline CG53) ed. London: Royal College of General Practitioners; 2007 